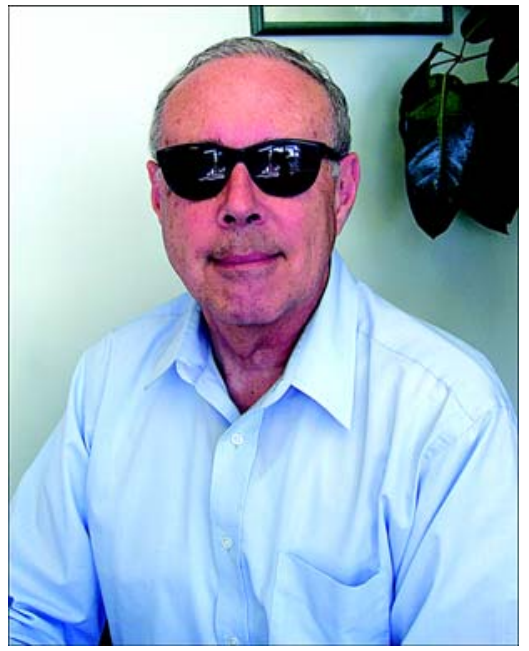

John Gardner, PhD

\title{
My vision
}

It may sound funny, but my blindness uncovered the vision that forged my ultimate path in life. When an eye operation for correcting my failing vision did the opposite, I was mid-career in my former life as a physics professor. That is when I began to understand the inadequacy of technologies that "filled the gaps" in communication for people who are blind or have other sensory disabilities.

The most significant gaps in technology for people who are blind were in mathematical and scientific tools. I immediately found that I was unable to read my students' theses because the formulas and diagrams were inaccessible to me. Innumerable other examples exist of inaccessible information that I needed to do my job or even just to live a full life. Unless information was neatly packaged in a text form readable by my computer's text screen reader, it was virtually inaccessible to me.

First I tried "people-power" to help fill the gaps. Students and aids described scientific diagrams to me in words. My wife described maps to me when we traveled. Words could not convey what I really wanted to know. Other creative solutions offered similarly unsatisfactory results. My situation was screaming for technologies that could hurdle the barriers and provide better access to this information.

Then my vision became clear. My struggles as a blind physics professor did not make me unique. In fact, quite the opposite was true. Numerous other blind professionals and students throughout the world were facing similar circumstances and barriers. I needed to use my skills as a research director to develop learning tools that would make information universally accessible. This is when my new course in life began.

In 1990, I founded the Science Access Project at Oregon State University (Corvallis, Oregon). This project, funded by the National Science Foundation, initiated the original research and development for several products that were eventually commercialized by ViewPlus Technologies, Inc (Corvallis, Oregon), the spin-off company that I started in 1996.

In 2000, ViewPlus Technologies released the first Tiger braille printer. Now, 6 years later, Tiger braille technology is famous throughout the world. Tiger braille printers were designed to give people who are blind access to the diagrams that created difficulties for me years ago. Now when I need to read diagrams, I simply print them on my Tiger braille printer for a highresolution tactile (i.e., raised) version of the display on the computer screen. If I am on vacation, I can print tactile maps of the area rather than tax my wife for verbal descriptions.

The latest Tiger technology adjusts to color and shading by providing lighter embossing for light colors and/or shades and harder embossing for darker colors and/or shades. Tiger braille printers can produce braille with raised pictures and diagrams, but these raised graphics are only usable by people who can read the braille labels describing the diagrams. In most 
countries, only 10 to 15 percent of people who are blind read braille. In 2005, ViewPlus introduced a new innovation that bridges this gap: the IVEO tactile-audio system (Figure). IVEO makes raised pictures speak so that they are not limited to braille readers. IVEO allows the user to read a detailed tactile diagram with audio feedback instead of braille labels, thereby making the diagram usable by more people.

IVEO is like a computer drawing program except that it speaks and uses a touch-sensitive pad that interacts with the software through a universal serial bus. I can print diagrams from the IVEO program to my Tiger braille printer and read them through touch and audio. I place the tactile printout on my IVEO Touchpad and text that I touch speaks. Graphical objects also speak if they have labels or descriptions in the file. I can enlarge small features or rescale diagrams if I need different tactile printouts.

I do not usually draw objects in IVEO, although I could with the IVEO Touchpad. Mostly, I import diagrams from other Microsoft Windows programs. One of the most impressive features of IVEO is the IVEO Converter. The IVEO Converter allows me to import information from any computer program into IVEO. So, if a document can be displayed visually on the computer screen, I can independently convert it to a format that I can tactually and audibly read with the IVEO Touchpad. Very complicated diagrams may still require "people power" for putting descriptions in the file, but most diagrams are understandable from the shape and text labels.

The IVEO tactile-audio system and Tiger braille printer are not just for people who are blind. The IVEO software has features for people with low vision or other disabilities. A new embosser, called Emprint, has added Hewlett-Packard Inkjet color printing to the tactile and braille output. Thus, users can create talking tactile documents that also have a

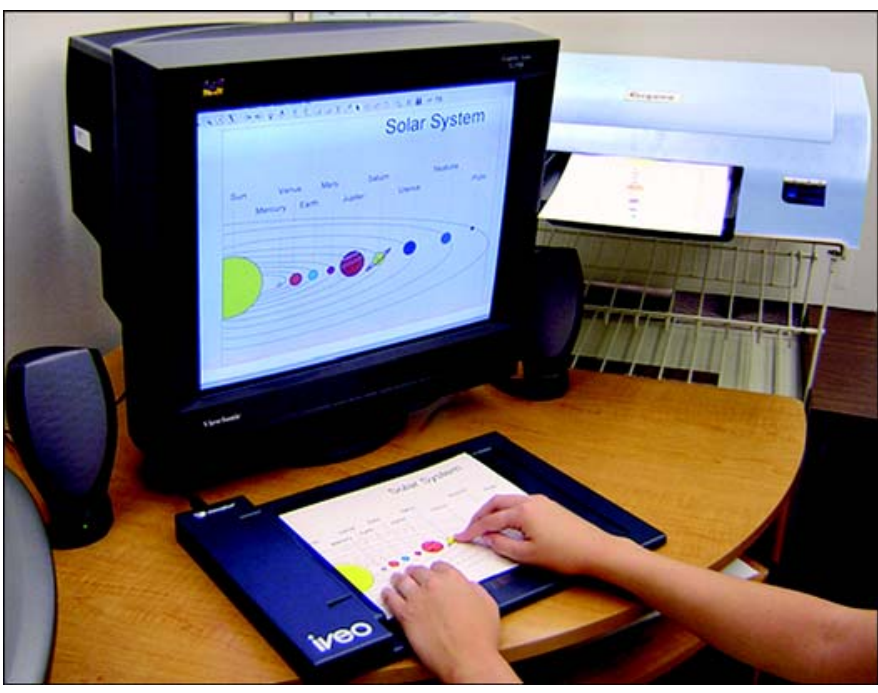

Figure.

Person with visual impairment reading diagram with IVEO tactileaudio system (ViewPlus Technologies Inc, Corvallis, Oregon).

rich visual interface. With these simultaneous visual, auditory, and tactile modalities, people with visual and learning disabilities have a complete, interactive learning environment and can use the learning method that works best for them.

I am no longer "mid-career," but I am driven by the success we have had in 10 years with ViewPlus. It all started by creating answers for myself, then for others like me and, ultimately, by searching for a better, more interactive way for all people to learn. I have many more plans for IVEO and for other tools that make learning more interactive and effective for all. I am still blind, but my vision is clear and my journey is just beginning.

\section{John Gardner, PhD}

Professor Emeritus, Department of Physics, Oregon State University, Corvallis, OR; President, CEO, ViewPlus Technologies Inc, Corvallis, OR Email: john.gardner@orst.edu

DOI: 10.1682/JRRD.2006.03.0031 